\title{
Business Leverages on Strategic Information Systems In
}

\section{Nigeria}

\author{
Ahaiwe Josiah \\ Department of Information Management Technology Department, Federal University of \\ Technology, Owerri - Nigeria \\ E-mail: jahaiwe@yahoo.com
}

\author{
Accepted: Feb 24, 2013 Published: March 17, 2013 \\ Doi:10.5296/ijld.v3i1.3389 URL: http://dx.doi.org/10.5296/ijld.v3i1.3389
}

\begin{abstract}
The dynamic growth of information technology (IT) in recent years has put Managers on their toes. Managers have come to recognize the alignment of business and information technology strategy as a key issue for their success. The purpose of this work is to build a framework on how Nigerian business organizations can build IT architecture in line with their business vision so as to be relevant in international market. It recognizes how organizations can take advantage of IT to bring considerable benefits and maximize profits for stakeholders.

In this work, an attempt is made to design a frame work for deploying IT architecture for business systems with a scope on organizations in Nigeria. The system consists of the organization's intranet, linked to the internet on which the organization's customer, suppliers and the branches can share resources and develop mutual relationship for business growth.
\end{abstract}

Keywords: Information strategy, Strategic information systems, business processes, Competitive strategy, Organizations, Business strategy, system architecture.

\section{Introduction}

Many technologies have had significant impacts on people's lives since the twentieth century, but none as profound as information technology (IT). The information technology revolution has had an enormous influence on how organizations are run or managed. Almost all the innovations in the practice of modern management have had their influence from the development of information technology. The emergence of global economy and the increasing knowledge-based nature of modern organizations are all integral part of information technology.

Many developing and third world countries are still battling to breakthrough In terms of development but it has not been very easy task for them as a result of technology. The mode of business processes are still at its primitive stages and all these has led to high cost of production and consequently decline in expected profit. According to O'Brein J (1999), Information systems is more than just a set of technologies that support workgroup and enterprise collaboration, efficient business operations or effective managerial decision making, it can change the way businesses compete.

Nigerian economy is today witnessing high cost of production and inflation. These problems are not necessarily due to economic forces known to us, but partly due to developed culture of 
wastages in time and material resource. As part of the solution, evaluation of our business processes in line with other developing countries have been suggested.

Many have reasoned that lack of performance is as a result of non application of information technology to our business processes. The purpose of this paper therefore is to build a conceptual framework on which the problem may be solved.

\section{THE THEORY OF COMPETITIVE STRATEGY}

Strategies are general approaches that illustrate how organizational goals can be achieved, and tactics are more specific guides to actions that would implement strategies, (O'Brien,1999). Ideally, in their strategic planning process, organizations try to develop firstly, a shared vision using variety of techniques, followed by the development of their mission, goals, strategies, and policies. Powell et al (2001). views business strategy as the tool that manipulates the resources and create competitive advantage, hence, viable business strategy may not be adequate unless it possess control over unique resources that has the ability to create such a unique advantage. Organizations will have to understand and deal with their environment. A superior understanding and representation of their environment leads to superior choices that they have to make. According to Gavetti G. (2011), some firms are endowed with better ways of representing the world around them than others. Superior representations lead to superior choices that are not easy for other firms to understand and copy.

Competitive advantage seeks to address some of the criticisms of comparative advantage Michael Porter proposed in 1985. Competitive advantage theory suggests that states and businesses should pursue policies that create high-quality goods to sell at high prices in the market. Porter emphasizes productivity growth as the focus of national strategies. Competitive advantage rests on the notion that cheap labor is ubiquitous and natural resources are not necessary for a good economy. The other theory, comparative advantage, can lead countries to specialize in exporting primary goods and raw materials that trap countries in low-wage economies due to terms of trade. Competitive advantage attempts to correct for this issue by stressing maximizing scale economies in goods and services that garner premium prices (Stutz and Warf, 2007). Competitive advantage occurs when an organization acquires or develops an attribute or combination of attributes that allows it to outperform its competitors. These attributes can include access to natural resources, such as high grade ores or inexpensive power, or access to highly trained and skilled personnel human resources, new technologies such as robotics and information technology either to be included as a part of the product, or to assist making it. Information technology has become such a prominent part of the modern business world that it can also contribute to competitive advantage by outperforming competitors with regard to internet presence.

The term competitive advantage is the ability gained through attributes and resources to perform at a higher level than others in the same industry or market (Christensen and Fahey 1984, Kay 1994, Porter 1980 cited by Chacarbaghi and Lynch, 1999). The study of such advantage has attracted profound research interest due to contemporary issues regarding superior performance levels of firms in the present competitive market conditions. "A firm is said to have a competitive advantage when it is implementing a value creating strategy not simultaneously being implemented by any current or potential player" (Barney 1991 cited by Clulow et al.2003, ). Successfully implemented strategies will lift a firm to superior performance by facilitating the firm with competitive advantage to outperform current or potential players (Passemard and Calantone, 2000). To gain competitive advantage a business strategy of a firm manipulates the various resources over which it has direct control and these resources have the ability to generate competitive advantage (Reed and Fillippi 1990 cited by Rijamampianina, 2003). Superior performance outcomes and superiority in production resources reflects competitive advantage (Day and Wesley 1988 cited by Lau, 2002). 
It is important to note here that during Reagan Administration in the United States, he realized that American industries were losing in international competition that he appointed a team of experts led by Michael Sekora to determine among other things: 1) Why US industries were losing their ability to compete in the world marketplace and 2) develop a solution to restore US industry's ability to compete. This project was tagged "Project Socrates". The Socrates team launched one of the most in-depth research undertakings ever conducted in the US intelligence community, producing ten key findings that became the basis for the "Socrates technology-based competitive strategy" system, and support tools for developing and executing competitive strategies.

Strategic information systems are systems that support or shape the competitive position and strategies of an organization and place the organization in a leadership position. An organization can survive and succeed in the long run if it successfully develops strategies to confront five well-known competitive forces that shape the structure of competition in its industry.

According to O'Brien J (1990), the competitive forces a an organization have to face include:

1. Rivalry of competitors within its industry

2. Threat of new entrants

3. Threat of substitutes

4. Bargaining power of customers

5. Bargaining power of suppliers

Various well-known competitive strategies can be developed to help an organization confront these competitive forces. These include among others:

1. Becoming a low cost producer of products and services

2. Finding ways to help suppliers or customers reduce their costs

3. Developing ways to differentiate products and services from competitors.

4. Finding new ways of doing business: a) develop new products \& services b) enter new markets or marketing segments. c) establish new business alliances d) find new ways of producing products/services e) find new ways of distributing products/services

5. Significantly expanding the company's capacity to produce goods and services. Expand into global markets - Diversify into new products and services - Integrate into related products and services.

6. Establishing new business linkages and alliances with customers, suppliers, competitors.

Competitive strategy therefore is a set of activities that enables an organization stay ahead of present or potential competition, thus superior performance reached through competitive advantage that ensures leadership position. Also it provides the understanding that resources held by a firm and the business strategy will have a profound impact on generating competitive advantage.

\section{STRATEGIC INFORMATION SYSTEMS}

According to Kroenke, D M. (2008), information system (IS) is any combination of information technology and people's activities that support operations, management and decision making. In a very broad sense, the term information system is frequently used to refer to the interaction between people, processes, data and technology. In this work, the term is used to refer not only to the information and communication technology (ICT) that an organization uses, but also to the way in which people interact with this technology in support of business processes. 
A Strategic Information System (SIS) is a system that is typically utilized by organizations to streamline and quicken the reaction time to environmental changes and aid it in achieving a competitive advantage. The strategic role of information systems in attaining organizations' vision involves using information technology to develop products, services, and capabilities that gives strategic advantages over the competitive forces it faces in the global marketplace.

Key features of the Strategic Information Systems are:

1) Decision support systems that enable the development of a strategic approach to align Information Systems (IS) or Information Technologies (IT) with an organization's business strategies

2) Primarily Enterprise resource planning solutions that integrate or link the business processes to meet the enterprise objectives for the optimization of the enterprise resources

3) Database systems with the "data mining" capabilities to make the best use of available corporate information for marketing, production, promotion and innovation. The SIS also facilitates identification of the data collection strategies to help optimize database marketing opportunities.

4) A real-time information System that intend to maintain a rapid-response and the quality indicators.

\section{STRATEGIC INFORMATION SYSTEMS PLANNING}

Strategic Information technology planning uses the organization's business vision and business drivers to create information technology architecture and tactical Information system plans for business use of information technology. An organization's Information systems architecture involves a unified framework for managing and operating information systems and resources in an organization-wide setting. The architecture is designed and built around the following principles:

- The organization-wide business needs and long-range strategic goals.

- Data and infrastructure as an investment with long-range value and benefits.

- System integration through sound design and use of applicable information technology standards.

- Coordination, collaboration, and shared resources such as data, systems, applications and support.

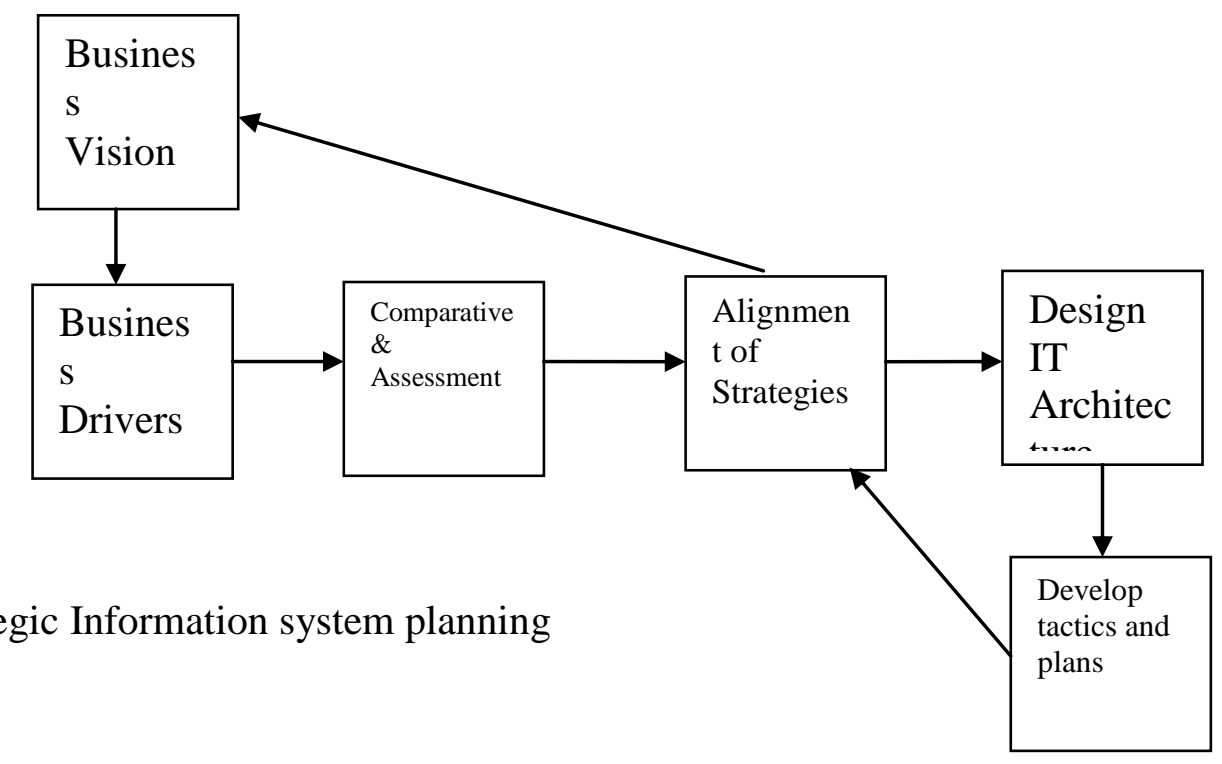

Figure: 1 Strategic Information system planning 


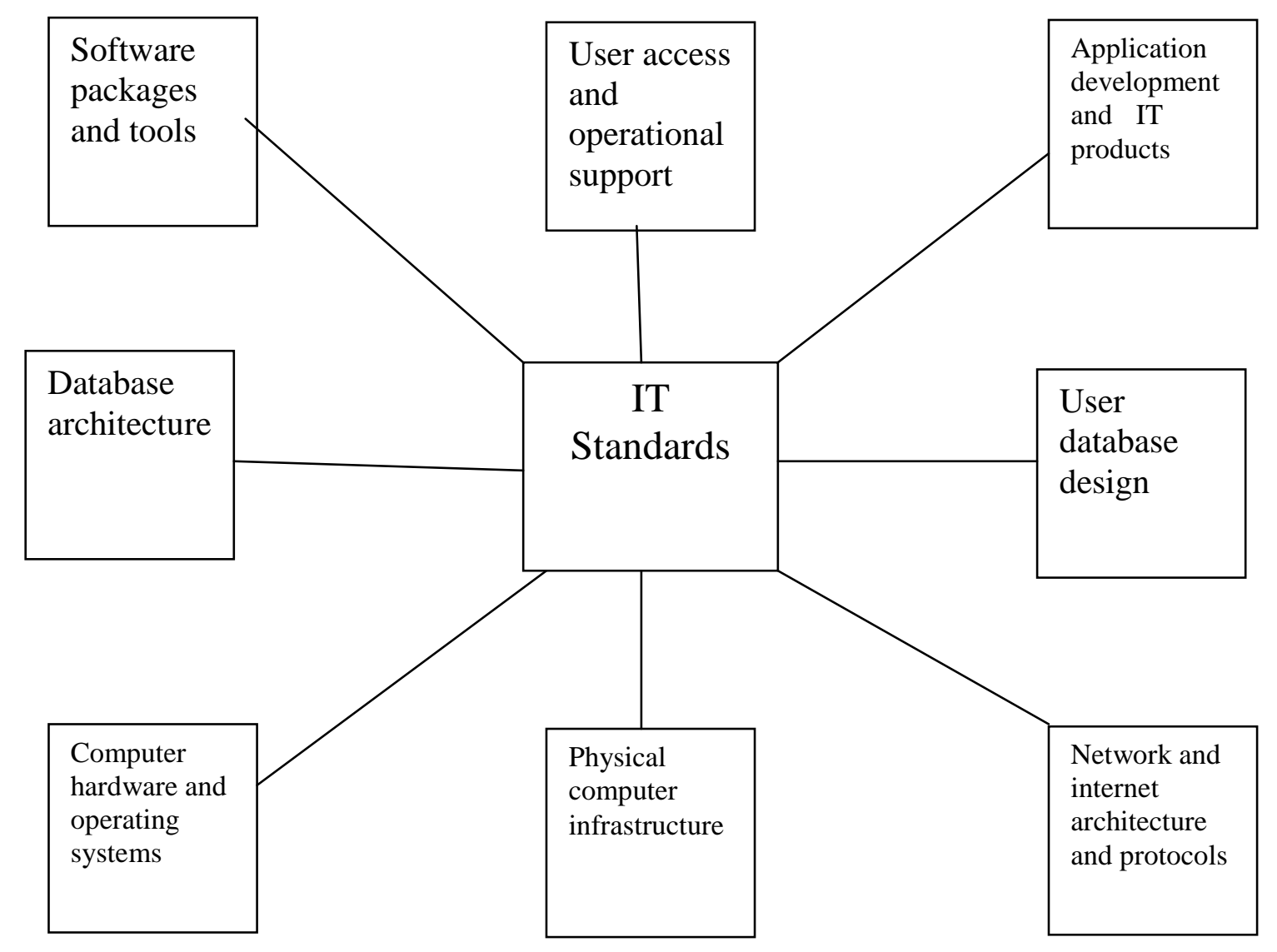

Figure 2 Components of an organization-wide information system architecture

\section{INFORMATION SYSTEMS IN NIGERIA}

"Despite the fact that there are presently many computer installations in Nigeria, the awareness of the potentials of these computers and their relevance to our national development and well-being is just emerging. The nation's response to the growing data processing needs, as contained in the National Development Policy Plans have continued to witness the importation and sale of many computer hardware and software to clients", (Alabi G. A, (1996). Today, there are more computer installations and more improved telecommunication systems than we had in 1996. The problem today is no longer in the availability of computers, but with the planning and utilization of information technology infrastructure to attain national economic goals. It is the purpose of this work to build a framework for organizations to leverage (take advantage) on information technology and information systems to attain their set goals which eventually interprets to national economic growth. With the existence of internet, competitions are no longer within Nigerian boarders but across international borders. The internet technology has drastically reduced time and geographical distances, thereby reducing cost of doing business across the globe. 


\section{INFORMATION TECHNOLOGY ARCHITECTURE}

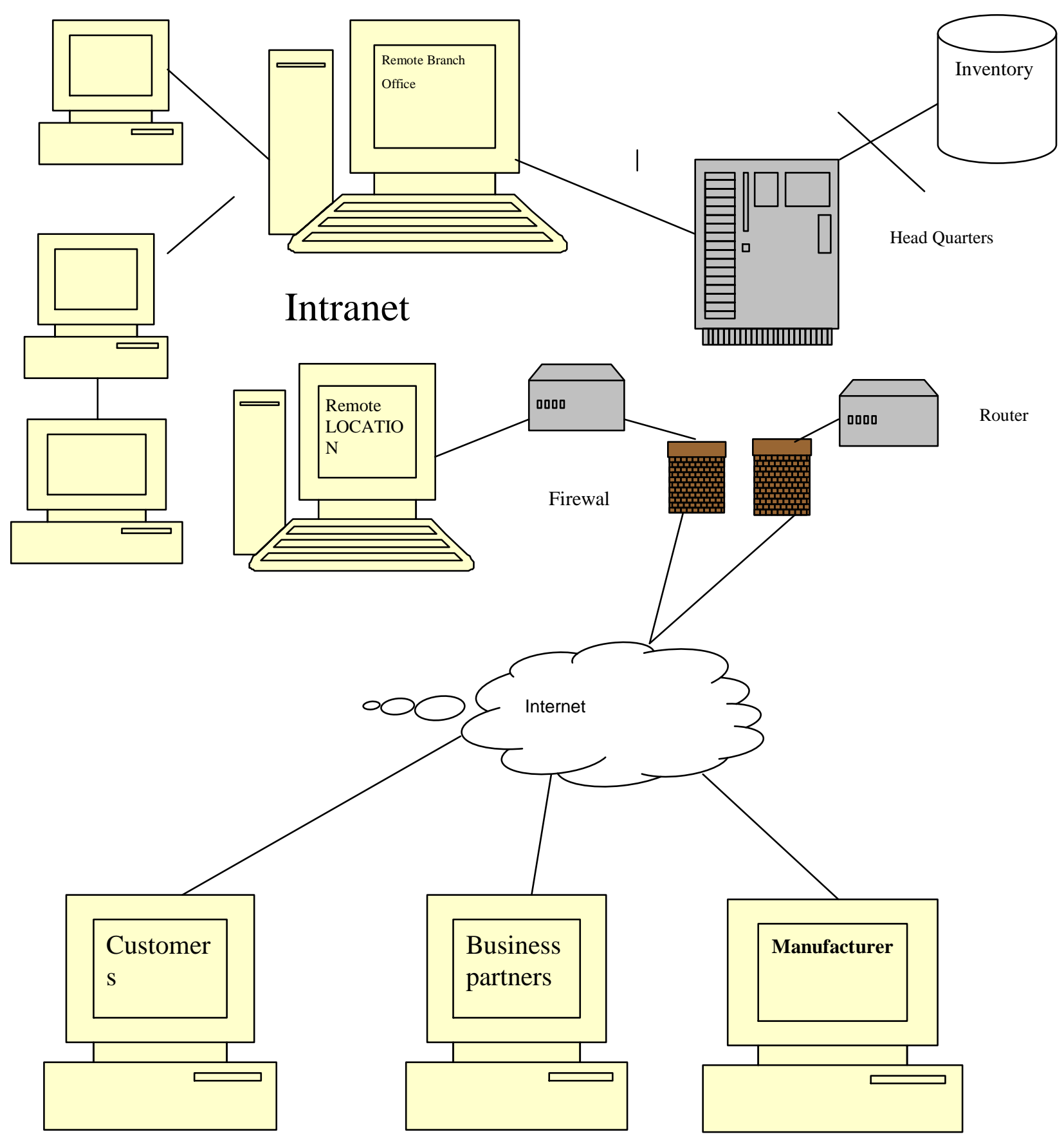

Figure3: Strategic Information Technology Architecture

\section{APPLICATION PROCEDURE}

An organization has to enable internet website to enable interactive marketing and electronic commerce and collaboration with customers and business partners.

Business partners will use the internet for Email, file transfer, discussion forum, and extranet access to organization's intranet resources. 
Customers will use multimedia website catalogs and purchase products and obtain services with interactive service and support.

Supplier will use extranet for E-commerce to access inventory, replenish stock, and send documents through electronic data inter-change (EDI) over protected or secured network links. Intranet links with remote employee sites will connect virtual teams for interactive communications, collaboration, and computing.

This architecture using internet, organizations in Nigeria can form business alliances and linkages such as: mergers, acquisitions, joint ventures, formation of 'virtual companies' and distribution agreements.

\section{Components of the Architecture}

The system will have Internet facing Web-based applications that can be accessed remotely by the users either within the confines of the organization or remotely. The following is list of the information technology (IT) infrastructure components of the system

- Firewall: A system designed to prevent unauthorized access to or from a private network. Firewalls can be implemented in both hardware and software, or a combination of both. Firewalls are frequently used to prevent unauthorized Internet users from accessing private networks connected to the Internet, especially intranets. All messages entering or leaving the intranet pass through the firewall, which examines each message and blocks those that do not meet the specified security criteria. There are several types of firewall techniques.

- Packet Filter: Looks at each packet entering or leaving the network and accepts or rejects it based on user-defined rules. Packet filtering is fairly effective and transparent to users, but it is difficult to configure. In addition, it is susceptible to Internet Protocol (IP) spoofing.

- Application Gateway: Applies security mechanisms to specific applications, such as File Transfer Protocol (FTP) and Telnet servers. This is very effective but can impose performance degradation. Circuit-Level Gateway: Applies security mechanisms when a Transmission Control Protocol (TCP) or User Datagram Protocol (UDP) connection is established. Once the connection has been made, packets can flow between the hosts without further checking.

- Proxy Server: Intercepts all messages entering and leaving the network. The proxy server effectively hides the true network addresses.

- Router: A router is a special purpose computer or software device that enables two or more dissimilar networks to communicate. Routers route traffic, which consists of Transmission Control Protocol/Internet Protocol (TCP/IP) packets.

- Host: A computer that is connected to a TCP/IP network, including the Internet.

- Server $(s)$ : A server is a dedicated computer that allows other computers to connect to it. Various types of servers exist which include the following:

Domain Name System

Web servers

Internet banking servers 
E-mail servers

Proxy servers

- PC Workstations: In networking, a workstation refers to any computer connected to a local area network. It could be a workstation or a personal computer.

- Intrusion Detection Systems: Intrusion detection is fundamentally the process of monitoring computer networks and systems for violations of computer policy.

\section{Conclusion}

Big and small organization world-wide have challenges, but they must be agile and smart to compete with others. With proper IT alignment to business vision and integrated approach to business, business intelligence for planning can be harnessed by agile organizations. This approach could be central to competitive advantage.

The Information Technology architecture here is used as a platform for the development of organization-wide enterprise systems, E-commerce systems, and improvement in customer relationship management. All these will interpret to development of various products and services that yields high profit.

\section{REFERENCES}

Alabi G. A (1996), Telecommunications in Nigeria, University of Pennslyvania - African Studies Center

Beynon-Davies P. (2009). Business Information Systems. Palgrave, Basingstoke

Chacarbaghi; Lynch (1999), Competitive Advantage: Creating and Sustaining Superior Performance by Michael E. Porter 1980, pp. 45

Clulow, Val; Gerstman, Julie; Barry, Carol (2003). "The resource-based view and sustainable competitive advantage: the case of a financial services firm". Journal of European Industrial Training 27 (5): 220-232.

Gavetti G. (2011) ,"Towards a behavioral theory of strategy”, organization science, ePub ahead of print April/11, http://orgsc.journal.informs.org/cgi/content/abstract/orsc/1110.064v1

Kroenke, D M. (2008). Experiencing MIS. Prentice-Hall, Upper Saddle River, NJ Lau, Ronald S (2002), "Competitive factors and their relative importance in the US electronics and

computer industries", International journal of operations and Production Management 22(1): 125-135.

O’Brein J(1999) Management Information Systems: Managing Information Technology in the Internetworked Enterprise, Irwin McGraw-Hill, USA.

O'Brien, J A. (2003). Introduction to information systems: essentials for the e-business enterprise.

McGraw-Hill, Boston, MA

Passemard; Calantone (2000), Competitive Advantage: Creating and Sustaining Superior Performance by Michael E. Porter 1980, pp. 18

Powell, Thomas C. (2001). "Competitive advantage: logical and philosophical considerations "Strategic Management Journal". 22 (9): 875-888.

Rijamampianina; Rasoava, Abratt, Russell, February, Yumiko (2003). "A framework for concentric 
diversification through sustainable competitive advantage". Management Decision 41 (4): 362.

Warf and Stutz, (2007). The world economy : resources, location, trade and development (5th ed. ed.). Upper Saddle River: Pearson, ISBN 0132436892. 